With the Compliments of Springer Publishing Company, LLC
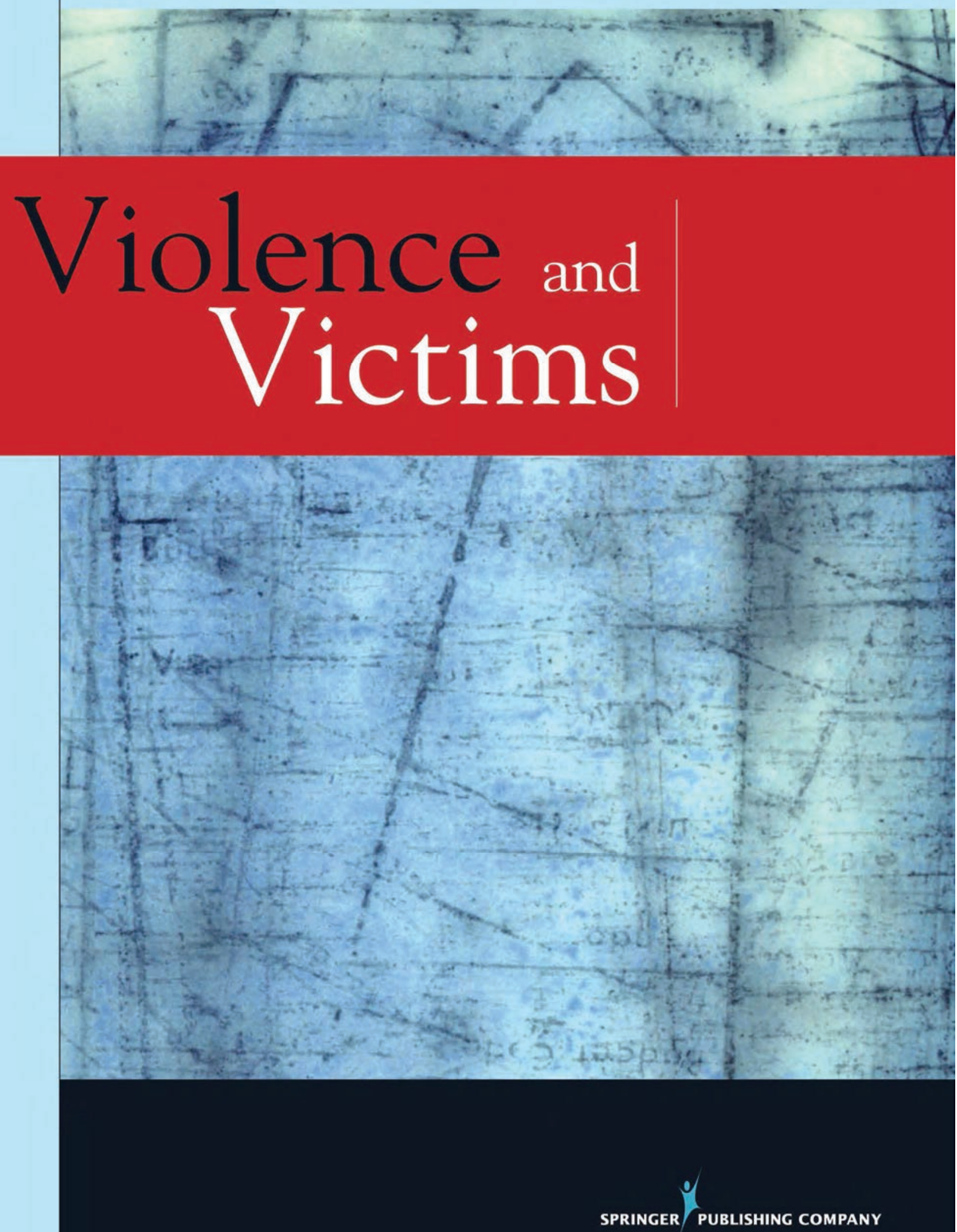

www.springerpub.com/vv 


\title{
The Difference Between Living and Dying: Victim Characteristics and Motive Among Nonfatal Shootings and Gun Homicides
}

\author{
Natalie Kroovand Hipple, PhD \\ Department of Criminal Justice, Indiana University, Bloomington \\ Lauren A. Magee, MS \\ School of Criminal Justice, Michigan State University, East Lansing
}

\begin{abstract}
Using both official and unofficial data sources, researchers examined nonfatal ( $n=617)$ and fatal shooting $(n=159)$ victim characteristics over an 18 -month period in Indianapolis. This research revealed that the typical shooting victim was male, non-White, almost 29 years old, had been arrested prior to inclusion in this study, and had been shot more than once. Interestingly, this research supports the notion that nonfatal shooting and homicide victims are different, especially as they relate to victim age, gunshot wound severity, and shooting motive. It highlights the need for better gun violence data collection beyond what currently exists. Striving for improved, more comprehensive cross-sector data collection has implications beyond just police policy and practice to include public health and prevention efforts.
\end{abstract}

Keywords: firearm violence; nonfatal shootings; homicide; motive; wound location

I

f one followed the life of a gunshot wound victim, he or she would quickly realize that gun violence is not solely the problem of law enforcement. That is, the law enforcement response to a gun violence incident is only one part of the response. Law enforcement is tasked with investigating and clearing cases, ideally by arrest. Emergency medical services respond to the scene to treat and transfer the victim from law enforcement to the local health care system. Beyond the law enforcement and emergency service responses, a complex range of social, environmental, and economic factors, among others, contribute to gun violence and must also be addressed to decrease the violence. Gun violence is complicated. Creating a better and more complete understanding of gun violence will serve to inform the broader audience of public safety beyond law enforcement and public health.

Furthermore, the call to address gun violence has increased in recent years, particularly at the federal level. The last 10-15 years has seen the development of numerous data systems charged with collecting information on firearm deaths, injuries, and the accompanying risks and behaviors (Annest \& Mercy, 1998). Medically sourced datasets such as the Nationwide Emergency Department Sample (NEDS), Nationwide Inpatient Sample (NIS), and Web-based Injury Statistics Query and Reporting System (WISQARS) as 
well as criminal justice-sourced datasets such as the Uniform Crime Reports (UCR) and, more recently, the National Incident-Based Reporting Systems (NIBRS) document the vast amount of firearm-related injuries that occur each year in the United States. These data systems are managed separately, each by a single federal agency but are not linked. Data are particularly limited as they relate to nonfatal firearm injuries because the systems largely collect data for surveillance, not research, and lack details needed for robust study and analysis (Annest \& Mercy, 1998).

Even with these numerous sources, Wellford, Pepper, and Petrie (2005) note that there is no formal and reliable data source to provide accurate, complete, and timely data capturing both the incidence and characteristics of firearm violence incidents. Because of this void in robust data on firearm violence incidents, many gun violence crime prevention policies and practices are based primarily on homicide data which, therefore, only presents a fraction of the picture of gun violence. And, given that a formal and reliable nationwide data source will not be available in the foreseeable future, there is a need for research comparing nonfatal and fatal shootings to confirm or deny these incidents are in fact similar and that, consequently, using homicide data is not enough to inform policy and practice.

\section{GUN VIOLENCE AND DATA SOURCES}

Firearms violence began to noticeably rise in the late 1980s and early 1990s. Homicides, as well as all violent crime, reached unprecedented levels in the mid-1990s. This increase in homicides was attributed to a rise in youth homicides (Blumstein, 1995; Cook \& Laub, 1998, 2002). Since the peak in 1993, there has been a nationwide decrease in homicides (Cohn et al., 2013; A. Cooper \& Smith, 2011; Planty \& Truman, 2013; Wellford et al., 2005). There are several factors that explain the decline as Beaman, Annest, Mercy, Kresnow, and Pollock (2000) suggest that the decrease in homicides in the late 1990s could be linked to the increase in critical medical care provided at trauma centers to gunshot wound victims.

Still, firearm violence was estimated to cost $\$ 174$ billion in 2010 (Howell, Bieler, \& Anderson, 2014). Cost estimates which include lost wages and lost quality of life as well as medical costs are more than 5 million dollars for a fatal gunshot wound (Nocera, 2013). The mean medical cost per firearm injury was about $\$ 17,000$ in 1994 , and gunshot injuries due to assault accounted for $74 \%$ of those injuries (Cook, Lawrence, Ludwig, \& Miller, 1999). The estimated cost for firearm assault injuries specifically increased to more than $\$ 23,000$ for inpatient treatment in 2010 (Howell \& Abraham, 2013). Nearly one half of the cost for medical treatment is paid by tax payers (Cook et al., 1999; Howell \& Abraham, 2013).

The majority of detailed criminological data available about gun violence focus on homicide incidents. Homicide data are considered valid and reliable because homicides are crimes that are most often brought to the attention of law enforcement and therefore easy to count when compared to other crimes (Black, 1970, 1980; Jackson, 1990). Research spanning decades reveals that homicide actors, both suspects and victims, are young, nonWhite males (Dobrin, 2001; Wolfgang, 1958), often with existing arrest records (Dobrin, 2001). Victimization is not random (Maxfield, 1987; Mustaine, 2010) because more often than not, the suspect and victim know each other (Reiss \& Roth, 1993), and suspects and victims interact with people who are similar to themselves both demographically and behaviorally (Dobrin, 2001). 
However, homicides are rare events (Piquero, MacDonald, Dobrin, Daigle, \& Cullen, 2005; Pridemore, 2005). According to the Federal Bureau of Investigation (FBI) UCR reports, there were an estimated 1,165,383 violent crimes that occurred nationwide in 2014. Homicides (i.e., all homicides, not just homicides by gun violence) comprise only a small portion of violent crime in the United States, just $1.2 \%$ of all violent crime in 2014. Aggravated assaults and robbery accounted for the majority of violent crimes at $63 \%$ and $28 \%$, respectively. Homicides occurred at a rate of 4.5 per 100,000 population in 2014 (Federal Bureau of Investigation [FBI], 2015). These statistics support the notion that homicides are a rare event compared to all other violent crimes across the United States (FBI, 2015). Furthermore, long-term trends indicate homicide incidents are becoming increasingly rarer because they decreased drastically since peaking in the 1990s from 9.3 homicides per 100,000 population in 1992 to 4.8 per 100,000 population in 2010 (A. Cooper \& Smith, 2011).

The FBI's UCR data, although the most widely used and cited data, are fraught with problems; their reliability and validity have long been debated by scholars (see, for example, Gove, Hughes, \& Geerken, 1985). Compounding these drawbacks, nonfatal shootings are not an official violent crime category within UCR. According to UCR definitions, a nonfatal shooting that occurs as a stand-alone crime (i.e., not, for example, during a robbery) is categorized as an aggravated assault. However, a nonfatal shooting that occurs as part of a robbery will be "lost" - that is, not counted — because the UCR Hierarchy Rule specifies that each incident only have one label and that label must be the most serious crime label occurring during the incident (FBI, 2004). In the case of a robbery with an aggravated assault (i.e., nonfatal shooting), that incident should be labeled a robbery by the reporting law enforcement agency.

Hospital and emergency department data are excellent sources for firearm injury counts because most states have laws mandating physicians or health care facilities report gunshot wound injuries to local law enforcement. Using the NEDS ${ }^{1}$ and the NIS, Howell and Abraham (2013) report there were 36,341 emergency department visits because of gun assault injuries in 2010 (a rate of 11.8 per 100,000 population). However, the Centers for Disease Control and Prevention (CDC) WISQARS dataset reported over 17,000 more nonfatal firearm injuries for the same year, 53,738 in 2010, suggesting an undercounting in NEDS (Howell \& Abraham, 2013).

At this time, despite the prevalence of gun violence in the United States, existing criminological and public health data sources are unable to provide the detail needed to create a clear picture of what gun violence looks like to inform policy and practice. More detailed and precise data points surrounding each incident and victim are needed specifically as they relate to nonfatal shootings. Likewise, given that public health scholars have noted its influence on fatality, wound location is one such variable to consider.

\section{Wound Location}

Although little research exists in the criminological literature on gunshot wound locations, two recent studies attempted to better understand the severity of a gunshot wound and how the bullet location relates to either survival or death. The Firearm \& Injury Center at Penn (2011) used four federal data sources along with professional journal articles to report on firearm injury deaths, nonfatal injuries, and their effects on society in the United States. The study found that nearly one third of all gunshot injuries are fatal, but fatality rates depend on the body part(s) injured, the type of weapon used, and the intent of the firearm 
event. For example, for every two people who are shot and survive, one person dies from a gunshot wound. However, self-inflicted gunshot wounds are more likely to be fatal indicating shooter motive is important.

Beaman et al. (2000) conducted a study using data from the National Electronic Injury Surveillance System (NEISS) ${ }^{2}$ to determine if there were differences in lethality of firearm injuries related to victim demographics and incident conditions. The NEISS collects patient information for emergency department visits resulting from injuries associated with consumer products. Participating NEISS hospitals are drawn from a nationwide probability sample (United States Consumer Product Safety Commission, n.d.). The research suggests that in the case of assault with a firearm, females experience higher gunshot lethality than males and Whites experience a higher gunshot lethality compared to nonWhites (Beaman et al., 2000). These results are notable given that most criminological research concludes that young, non-White males are the primary population involved and affected by firearm violence. Beaman et al. found that the majority of deaths were caused by a gunshot wound to the head, and those victims shot in the head are more than 3 times as likely to die compared to gunshot wounds to other areas of the body. Like the Firearm \& Injury Center at Penn (2011) study, they suggest motive specifically as a contributing factor to gunshot wound location and lethality. Specifically, suicide or self-inflicted gunshot wounds and intimate partner violence are offered as hypotheses for increased fatality rates for head wounds and females (Beaman et al., 2000).

Although the gunshot wound injury location influences the odds of death, Beaman et al. (2000) also advise that injuries with the highest lethality are the result of the shooter having the greatest control over the weapon (i.e., intentional) compared to the gunshot wounds where the shooter has no control (e.g., while shooting from a moving vehicle), which produce the lowest level of severity. These findings suggest that victims of nonfatal shootings are more likely to survive because of incident circumstances and the body part affected by the gunshot wound. Similarly, the Firearm \& Injury Center at Penn (2011) found that more than $70 \%$ of nonfatal injuries were gunshot wounds to the legs and arms, which result in a lower fatality rate.

Finally, Grommon and Rydberg (2014) examined the correlates of victim gunshot wound severity in nonfatal shootings. The older the victim and if he or she knew the shooter increased wound severity. They also found that victims who refused to provide information to law enforcement beyond basic details of the incident (i.e., refused to cooperative with police) were more likely to suffer from severe gunshot wounds. This finding suggests shooting motive may influence victims' willingness to provide information to law enforcement. However, their data source, police incident reports produced immediately following an incident, had considerable missing data for some predictor variables and did not include fatal injuries (i.e., homicides). They suggest a combination of both public health and criminal justice data sources for enhanced understanding of wound severity as it relates to shooting incidents.

\section{Motive}

Hospital and emergency department data on shooting victims includes criminal as well and noncriminal intent (i.e., motive) information. Correspondingly, law enforcement responds to all gunshot wounds reported either through 911 or by emergency department personnel $^{3}$; however, law enforcement is most focused on crimes against persons rather than self-inflicted gunshot wound cases or accidental shooting cases. Available evidence 
demonstrates victims and offenders involved in violent crime often share demographic as well as individual characteristics (Dobrin, 2001), victims and suspects also tend to be known to one another (Reiss \& Roth, 1993), and the violence tends to be situated in relational conflicts (Felson \& Steadman, 1983; Luckenbill, 1977) or within social networks (Papachristos, Wildeman, \& Roberto, 2015). The relational conflicts and the motives behind these conflicts have long been of interest to researchers because motive has long been considered a defining characteristic of homicides (Wolfgang, 1958), and the research supports this attention. These studies on victims and offenders have noted the role of disputes, domestic violence, and robbery, for example. Other classifications have included arguments, homicides related to the commission of another crime (e.g., robbery, rape, burglary), drugs, gangs, and unknown (Zahn \& McCall, 1999); many homicides are retaliatory (Block, 1977; Wolfgang, 1958).

Researchers have typically categorized homicides into dichotomous categories along several variables including relationship-primary and secondary or stranger and nonstranger (see for example, Decker, 1993). Motives for killing (although not limited to gun homicides) have been similarly categorized into dichotomies-instrumental or expressive (see, for example, Block, 1976; Miethe \& Drass, 1999) with common characteristics to each type. More recently, Pizarro (2008) disaggregated these categories further finding differences across four motive types: domestic, drug, robbery, and interpersonal dispute.

Little research exists on the specific details that differentiate between gun homicides and nonfatal shooting incidents. The belief that the only difference is "good medicine and/ or poor aim" is popular but untested, and homicide research would suggest there are more complicated incident level variables such as motive influencing wound location and therefore fatality. The data presented here will document differences in gun violence incident characteristics that may predict the incident type: nonfatal shooting or homicide. Data will examine nonfatal and fatal gun violence incidents in a large mid-western city paying particular attention to victim demographics, the gunshot wound endured by victims, and incident details such as motive. The goal of this work is to consider differences between fatal and nonfatal shooting incidents using a combination of medical ${ }^{4}$ and criminal justice data.

Understanding the severity level of gunshot wound locations will help public safety officials create more effective gun violence prevention programs and improve the survivability of gunshot wounds through better access to care and treatment (Beaman et al., 2000). More important, the role of motive as it relates to wound location and incident type cannot be ignored because motive likely influences incident outcome. Supplementing existing homicide data with detailed data on nonfatal shootings will help create a more accurate picture of gun violence. Enhanced data will support law enforcement and public health agencies to better direct prevention and response resources. This study seeks to strengthen current research by using law enforcement data to examine gun violence victims, fatal and nonfatal, the gunshot wounds they endure, and, when possible, placing these incidents in the context of motive.

\section{CURRENT STUDY}

The current research draws on data collected by the Marion County Non-Fatal Shooting Review Board which convenes in Indianapolis, Indiana. Indianapolis spans $361 \mathrm{mi}^{2}$ and had an estimated population of 848,788 people in 2014 (United States Census Bureau, 2015). Overall, Indianapolis was ranked 1 of the 10 most violent cities in the nation in 
2014 with a homicide rate of 16 per 100,000 population and a violent crime rate of 1,255 per 100,000 population (FBI, 2015). The City of Indianapolis experiences approximately 400 nonfatal shootings each year, occurring at a rate of more than one firearm violence assault victim each day (Indianapolis Non-Fatal Shooting Review Board, 2014) or 48 per 100,000 population each year. In Indianapolis, nonfatal shooting victims are almost 4 times more frequent than gun-related homicide victims. In 2014, there were 408 nonfatal shooting victims and 114 gun homicide victims. ${ }^{5}$ This study will examine nonfatal shootings and gun homicides occurring in Indianapolis, Indiana, from January 1, 2014, through June 30, 2015. The overarching research question (RQ) guiding this study is

RQ: Are nonfatal shooting victims different than gun homicide victims?

To answer this overarching question, researchers ask

RQa: Are nonfatal shooting victims different from gun homicide victims along basic demographic variables such as age, race, gender, arrest record, and multiple gunshot wounds?

RQb: Does gunshot wound severity differ between nonfatal shooting and gun homicide victims?

RQc: Does motive predict gunshot wound severity?

RQd: Do victim demographics, wound location severity, multiple gunshot wounds, and incident motive predict a nonfatal shooting victim or a gun homicide victim?

\section{Data Sources}

Data on nonfatal shooting incidents and victims come from the Marion County Non-Fatal Shooting Review Board database. The database is populated using information from a combination of internal police documents and police incident reports as well as data from the prosecutor's office and regular nonfatal shooting crime incident review meetings (Hipple, McGarrell, O'Brien, \& Huebner, 2016). Local researchers enter, code, and clean data by hand based on the evidence-based practices of the Milwaukee Homicide Review Commission (see for example, Azrael, Braga, \& O'Brien, 2013; O'Brien, Woods, \& Cisler, 2007). Gun homicide information is retrieved from an internal police department homicide database populated and maintained by the Indianapolis Metropolitan Police Department (IMPD).

These data do not include victims from all nonfatal gunshot incidents; rather, for this study, a nonfatal shooting incident is defined as an incident that would be designated as an aggravated assault by the FBI's UCR. UCR defines an aggravated assault "as an unlawful attack by one person upon another for the purpose of inflicting severe or aggravated bodily injury" (FBI, 2013). Self-inflicted and accidental nonfatal shootings were therefore excluded. Researchers chose these parameters for nonfatal shootings because of the criminal nature of the person-on-person violence and the expectation that the police and prosecutor's office can play a role in reducing such gun violence. In an effort to capture a true count of nonfatal shootings, the Hierarchy Rule was not applied to each shooting victim (FBI, 2004). Researchers counted every shooting victim regardless of UCR incident hierarchy. Gun homicide data were extracted from the police department homicide records management system and include all criminal homicides where the cause of death was a gunshot wound. In addition, data on gun homicide incidents and victims were collected from autopsy reports, coroner field deputy reports, and death certificates. The 18-month study period (January 1, 2014, to June 30, 2015) includes a sample containing 776 total gunshot victims (617 nonfatal shooting victims and 159 gun homicide victims). 
Independent Variables. The unit of analysis for all independent variables but one was the shooting victim. Victim race is a dichotomous measure (non-White $=0$ and White $=1)$. Non-White $(n=636)$ included 16 Hispanics and 4 Asians. Victim gender is coded as male $=0$ and female $=1$. Age is the victim's age at the time of the incident. Arrest record is also dichotomous, no (i.e., zero previous arrests) $=0$, yes $=1$. Researchers determined the existence of a previous arrest record for victims if prosecutor records indicated the victim had a local unique identifier (i.e., Gallery number) specific to someone who has been arrested in Marion County. The juvenile detention facility issues a similar unique identifier to juveniles processed at that location (i.e., Quest number). Arrest record was coded yes $=1$ if the victim had an associated Gallery or Quest ${ }^{6}$ number and no $=0$ he or she did not. Arrest records were limited to Marion County.

For the purposes of this study, a gunshot wound was defined as a penetrating injury caused by a projectile weapon with a powder discharge (Beaman et al., 2000). For both nonfatal shooting and gun homicide victims, researchers coded the gunshot wound location(s) according to the Abbreviated Injury Severity Scale (AIS; Baker \& O'Neill, 1976; Baker, O’Neill, Haddon, \& Long, 1974). The categories (Table 1) are based on an adaptation of the AIS, which provided researchers with a simple numerical method for ranking injuries by severity (Linn, 1995). Although there are newer versions of the AIS that are currently in use in the medical field, these scales require more knowledge of the internal injuries resulting from the gunshot wound. The police records used for this research did not provide the kind of detailed medical information for shooting victims needed to use the most recent version of the AIS; therefore, this study used the 1990 version which ranks severity level by body part. Researchers coded each victim's injury site location by body part(s). If the victim endured multiple gunshot wound locations, the researchers coded the bullet wound location with the highest severity based on the AIS

TABLE 1. Wound Location Coding Scheme

\begin{tabular}{lcc}
\hline Body Part & Code & Severity Level \\
\hline Head & 2 & Most severe \\
Neck & 2 & Most severe \\
Chest & 2 & Most severe \\
Shoulder & 1 & More severe \\
Stomach & 1 & More severe \\
Back & 1 & More severe \\
Hip & 1 & More severe \\
Buttocks & 1 & More severe \\
Pubic region & 1 & More severe \\
Arm & 0 & Least severe \\
Leg & 0 & Least severe \\
Hand & 0 & Least severe \\
Foot & 0 & Least severe \\
\hline
\end{tabular}


but noted multiple gunshot wounds. Next, the researchers recoded the records into three categories based on the severity level of the gunshot wound location.

Researchers collected data for the motives driving each nonfatal shooting and gun homicide from internal police records. Motive, unlike the other independent variables, was coded at the incident level. That is, if an incident had more than one victim, the motive attached to all the shooting victims was the same because researchers assumed that there was a primary motive for the shooting incident not for each victim. For the nonfatal shootings, each researcher coded every incident for one of nine motives (Table 2). Any disagreements were discussed and then a decision made on the final assigned motive. Generally speaking, the researchers tried to determine the primary reason the shooting occurred, that is, was it over drugs, did it occur while someone was being robbed, was the shooting between intimate partners (i.e., domestic), or was there a dispute related to a card or dice game (i.e., gambling). The motive was coded as retaliation only if the victim or others present indicated they felt it was in retaliation for a previous event. A motive was coded as recklessness if the shooting appeared to be random such as someone shooting indiscriminately or into the air. Physical fights were distinguished from arguments by what was going on at the time of the actual shooting. So, a verbal altercation that turned physical and then someone was shot was coded as a physical fight. A situation where individuals were yelling at one another

TABLE 2. Motive by Victim Type $(N=776)$

\begin{tabular}{|c|c|c|c|c|c|c|}
\hline \multirow[b]{2}{*}{ Motive } & \multicolumn{2}{|c|}{ Nonfatal } & \multicolumn{2}{|c|}{ Fatal } & \multicolumn{2}{|c|}{ Total } \\
\hline & $n$ & $\%$ & $n$ & $\%$ & $n$ & $\%$ \\
\hline Robbery & 88 & 14.3 & 28 & 17.6 & 116 & 14.9 \\
\hline Argument & 106 & 17.2 & 23 & 14.5 & 129 & 16.6 \\
\hline Domestic & 13 & 2.1 & 7 & 4.4 & 20 & 2.6 \\
\hline Gambling & 2 & 0.3 & 4 & 2.5 & 6 & 0.8 \\
\hline Recklessness & 11 & 1.8 & 3 & 1.9 & 14 & 1.8 \\
\hline Drugs & 37 & 6.0 & 61 & 38.4 & 98 & 12.6 \\
\hline Physical fight & 32 & 5.2 & 2 & 1.3 & 34 & 4.4 \\
\hline Retaliation/Revenge & 23 & 3.7 & 15 & 9.4 & 38 & 4.9 \\
\hline Other $^{\mathrm{a}}$ & 10 & 1.6 & 6 & 3.8 & 16 & 2.1 \\
\hline Unknown & 295 & 47.8 & 10 & 6.3 & 305 & 39.3 \\
\hline
\end{tabular}

aThe "Other" category included money (i.e., not related to any other motive category), unintended or incorrect target, gang, and accidental/self-inflicted. In the case of accidental/ self-inflicted, these were situations where the victim did not admit to shooting himself or herself, but in the opinion of medical personnel and/or police personnel, an accidental or self-inflicted wound seemed the most likely scenario. These cases remained in the sample because they met the definition of an aggravated assault as reported by the victim. That is, unless there was an eye witness or other irrefutable evidence to contradict the reported assault, the police department reported it as an assault. 
then someone was shot was coded as an argument. If the data source did not indicate a motive, it is plausible that the detective did not know the motive at the time the narrative was completed (i.e., within 24 hours of the shooting), the motive was therefore coded "unknown."

Motive for the gun homicide incidents was completed by the homicide detective assigned to the case and retrieved from that internal police database. Readers will note the large number of unknown motives for nonfatal shooting victims compared to gun homicides. The data source used to identify motive for nonfatal shooting victims is not updated after it is initially completed. That is, the police department maintains a homicide database where all details of each case are updated as they become known to the detective. No such data source exists for nonfatal shootings, and therefore, a motive that takes a few days to emerge may never be known to the researchers.

\section{Findings}

RQa: Are nonfatal shooting victims different from gun homicide victims along basic demographic variables such as age, race, gender, arrest record, and multiple gunshot wounds?

Table 3 displays the race, gender, and age for the sample. There were 617 nonfatal shooting victims and 159 gun homicide victims for a total of 776 gunshot wound victims. More than $80 \%$ of nonfatal shooting victims were non-White; they were overwhelmingly male $(88.2 \%)$ and were on average 28 years old. Gun homicide victims were very similar, non-White and male, but tended to be older with a mean age of 32 years. Both victim types had been arrested prior to his or her "qualifying event" and had also been shot more than once (68\%). These findings support previously discussed research by Dobrin (2001) and Wolfgang (1958) among others as to the demographic characteristics of individuals involved in shootings. Interestingly, there were two independent variables that revealed statistically significant differences between nonfatal shooting victims and gun homicide victims: age and number of gunshot wounds. A $t$ test revealed that nonfatal shooting victims had an average age that was younger than gun homicide victims (27.8 and 32.3 respectively; $p=.035$ ). This finding supports previously discussed research by Grommon and Rydberg (2014) suggesting older victims suffer from more serious gunshot wounds. Here again, relying solely on gun homicide data does not explain the full picture of gun violence considering perhaps there are other circumstances that explain why younger victims are less likely to suffer more serious gunshot wounds than older victims. Further, chi-square analysis revealed no significant differences between nonfatal shooting victims and gun homicide victims regarding race, gender, and arrest record. However, the relationship between victim type and multiple gunshot wounds was significant $(p=.000)$. This finding is noteworthy and somewhat counterintuitive because, as mentioned, nonfatal shooting victims were more likely to have multiple gunshot wounds (74\%) where most gun homicide victims did not have multiple gunshot wounds (47\%). Therefore, wound location and severity are important factors.

RQb: Does gunshot wound severity differ between nonfatal shooting and gun homicide victims?

Next, researchers examined the gunshot wound severity for each victim. As Table 3 indicates, $68 \%$ of victims in the sample sustained more than one gunshot wound. As noted earlier, because exact wound location was sometimes difficult to discern and nonfatal shooting wound information was considerably less detailed than homicide wound location, 


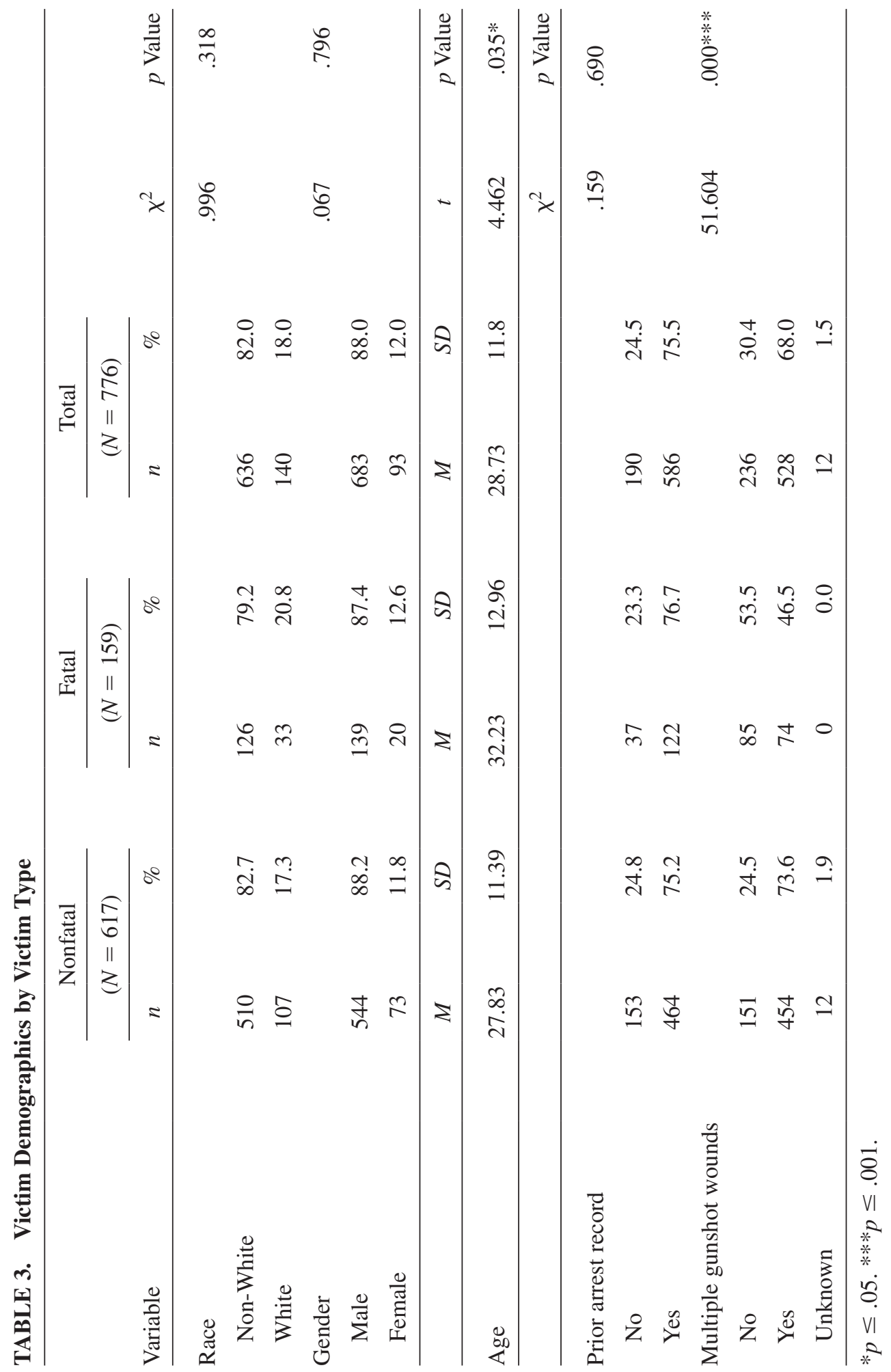


TABLE 4. Wound Severity by Incident Type

\begin{tabular}{|c|c|c|c|c|c|c|c|c|}
\hline \multirow[b]{3}{*}{ Severity Level } & \multirow{2}{*}{\multicolumn{2}{|c|}{$\begin{array}{c}\text { Nonfatal } \\
(N=603)\end{array}$}} & \multirow{2}{*}{\multicolumn{2}{|c|}{$\frac{\text { Fatal }}{(N=159)}$}} & \multirow{2}{*}{\multicolumn{2}{|c|}{$\frac{\text { Total }}{(N=762)}$}} & \multirow{3}{*}{$\frac{\chi^{2}}{224.787}$} & \multirow{3}{*}{$\frac{p \text { Value }}{.000^{* * *}}$} \\
\hline & & & & & & & & \\
\hline & $n$ & $\%$ & $n$ & $\%$ & $n$ & $\%$ & & \\
\hline Least severe & 333 & 55.2 & 2 & 1.3 & 335 & 44.0 & & \\
\hline More severe & 142 & 23.5 & 26 & 16.4 & 168 & 22.0 & & \\
\hline Most severe & 128 & 21.2 & 131 & 82.4 & 259 & 34.0 & & \\
\hline
\end{tabular}

$* * * p \leq .001$.

researchers chose to code one wound location per victim, that being the most serious wound location. There were 14 nonfatal shooting victims where researchers were unable to determine the exact wound location, thus reducing the total victim sample to 762 individuals. Table 4 displays the gunshot wound severity according to incident type. The majority of gunshot wound victims sustained less serious wounds (44\%). Still, as expected, there is a clear delineation surrounding wound severity between nonfatal shooting victims and gun homicide victims. A chi-square analysis shows that the relationship between gunshot wound location and incident type was significant $(p=.000)$, suggesting that where a bullet strikes a victim is important in determining survival and understanding these factors may help future public safety response and prevention efforts. These results support previous research discussed by Beaman et al. (2000) that a victim with more critical gunshot wounds is more likely to die than a victim with less critical gunshot wounds. Although this conclusion seems obvious, interestingly, $45 \%(n=270)$ of nonfatal shooting victims' wounds were categorized as either "more severe" or "most severe." This finding differs slightly from previously discussed research from the Firearm \& Injury Center at Penn (2011), which found the majority of nonfatal gunshot injuries were to the legs and arms, therefore suggesting there may be another contributing factor in the difference in gunshot wound severity between nonfatal shooting and gun homicide victims, such as the motive of the incident.

RQc: Does motive predict gunshot wound severity?

To answer this research question, researchers first sought to determine if the motive of a shooting incident could predict the gunshot wound severity of the victim. In this case, the dependent variable (gunshot wound severity) is captured at the ordinal level; therefore, researchers used ordinal logistic regression. The ordinal level dependent variable and the fact that the model passed the test of parallel lines $\left(p=.494, \chi^{2}=8.405\right)$ made ordinal regression the better statistical method over multinomial logistic regression.

Table 5 displays the results of the ordinal logistic regression. When the shooting motive was known, robbery, argument, domestic, drugs, retaliation/revenge, and other all produced statistically significant results suggesting they influence the severity of a shooting victim's gunshot wound. Odds ratios $(O R)$ with values greater than one reflect positive effects. The odds of a victim suffering from a more severe gunshot wound increases by almost 2 times for robbery and argument $(O R=1.59$ and 1.84 , respectively) and almost 3 times for a domestic and other shooting motive, relative to unknown motives ( $O R=2.59$ 


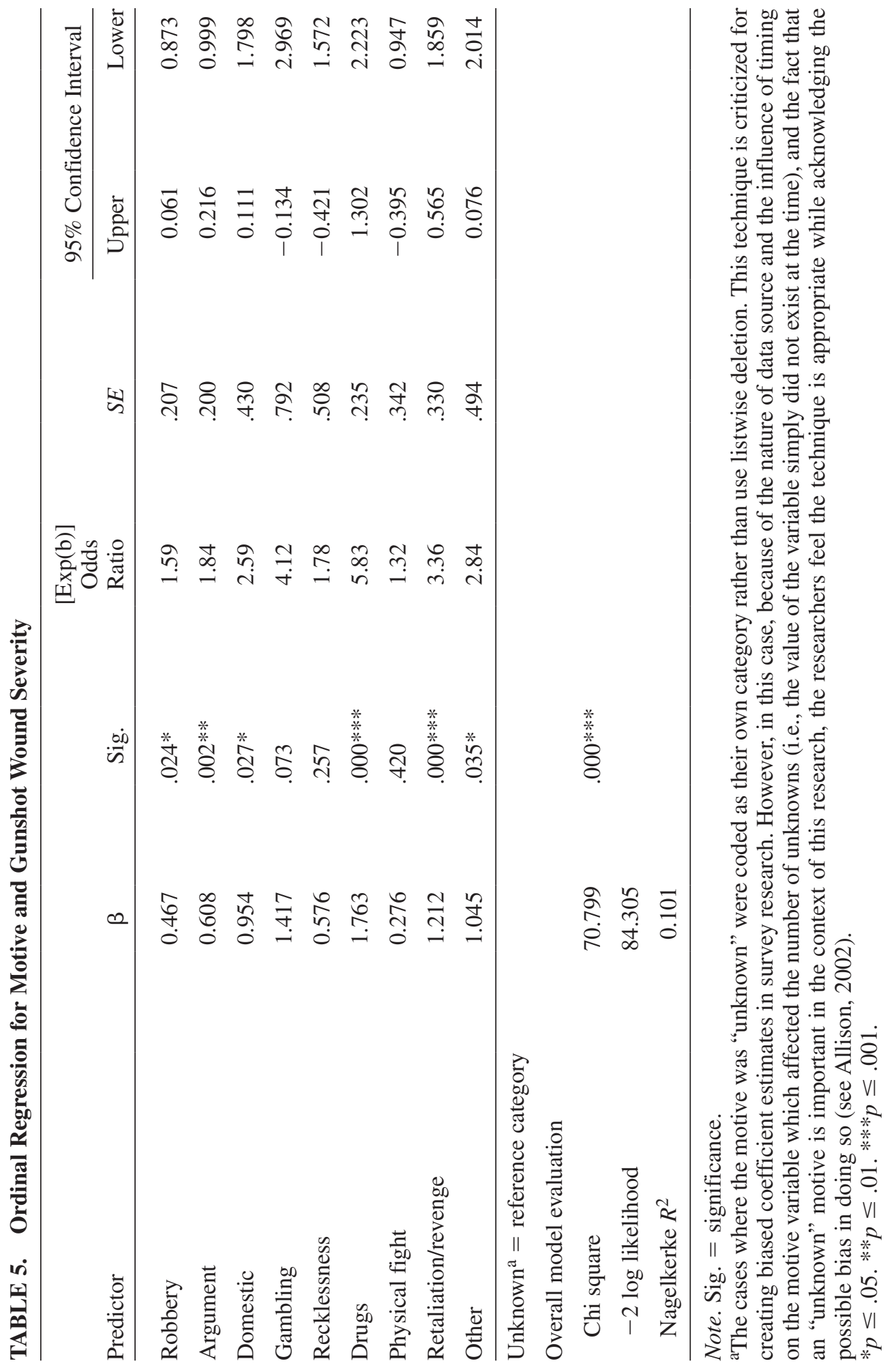


and 2.84, respectively). A victim's odds of suffering from a more severe gunshot wound increases more than 3 times when the shooting motive is retaliation/revenge and almost 6 times when the shooting motive is drug-related, relative to unknown motives $(O R=3.36$ and 5.83), respectively. Therefore, a victim who is shot during an incident that is retaliation/revenge-related or drug-related is more likely to suffer a more serious gunshot wound than victims of shootings where the motive is unknown. These findings support previously discussed research by the Firearm \& Injury Center at Penn (2011) and Beaman et al. (2000) that the intention (i.e., motive) of the shooting is a contributing factor to gunshot wound severity and is an important factor in understanding all gun violence. The shooting motives of gambling, recklessness, and physical fight did not reach the level of statistical significance and therefore had no effect on the level of gunshot wound severity a victim experienced.

RQd: Do victim demographics and wound location severity predict a nonfatal shooting or gun homicide?

Finally, researchers entered all the significant variables from the previous analyses into a binary logistic regression to estimate their effects on victim type (Long, 1997). Although not significant in the chi-square analyses, race and gender were also included in the logistic regression as control variables (Table 6). Researchers performed multicollinearity diagnostics for all the independent variables, and both the tolerance levels and variance inflation factors all came back within the normal ranges of .99 and 1.00, respectively, indicating multicollinearity was unlikely to be an issue.

Gunshot wound severity was a significant positive predictor of incident type $(p=.000)$. For victims, an increase in gunshot wound severity from "least severe" to "more severe" increased his or her odds of being a homicide victim by almost 24 times $(O R=23.82)$. An increase in gunshot wound severity from "more severe" to "most severe" increased an individual's odds of being a homicide victim by 130 times $(O R=130.2)$. When known, the shooting motives of robbery, argument, domestic, drugs, retaliation/revenge, and other all reached statistical significance $(p<.05)$. A victim who was shot during a robbery or domestic incident increased his or her odds of being a homicide victim by approximately 7 times $(O R=6.52$ and $O R=7.08$, respectively). A shooting victim where the motive was retaliation/revenge or other increased his or her odds of dying as a result of the shooting by approximately 10 times $(O R=9.78$, and $O R=11.30)$. Whereas a victim being involved in an argument only increased the odds of him or her dying by 3 times $(O R=3.68)$. An individual had the highest odds of being a homicide victim when he or she was involved in a drug-related shooting as a drug-related shooting increased an individual's odds of dying by almost 23 times. Following previous models, race, gender, age, arrest history and multiple gunshot wounds did not reach statistical significance and therefore did not affect fatality. Lastly, to examine the ability of the full model to predict gun violence incident type, researchers examined the area under the curve (AUC). The AUC was .922 which indicates a good model (DeMaris, 2004). Furthermore, although these findings are unable to explain why some gunshot wound victims survive and others do not, they do suggest that the motive of an incident is an important characteristic of all gun violence, not just homicide, as previously discussed research suggests (see Block, 1977; Wolfgang, 1958; Zahn \& McCall, 1999). Understanding the circumstances and gunshot wound severity of gun violence incidents, both fatal and nonfatal, can help law enforcement and public health agencies better direct their response and prevention efforts. 


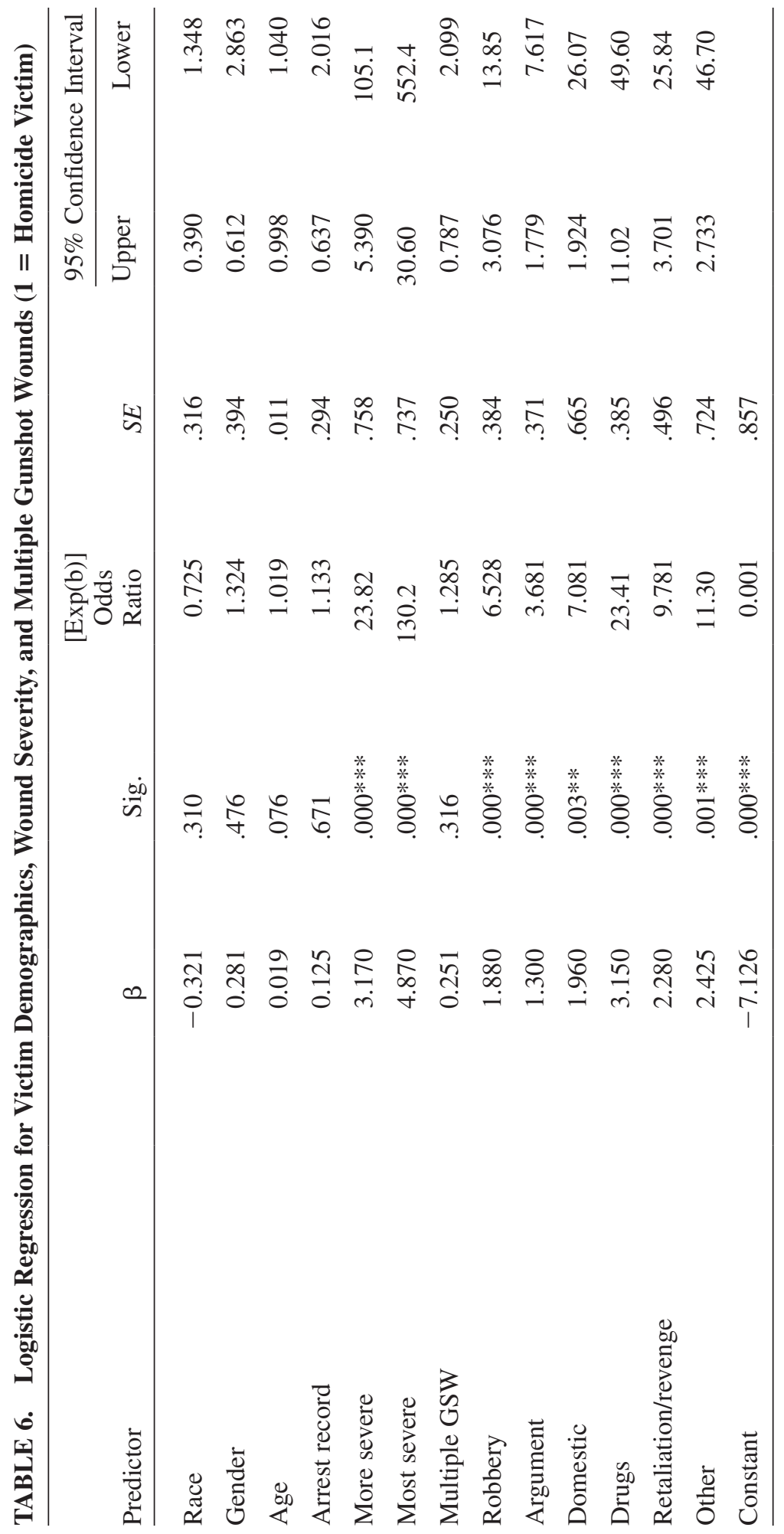




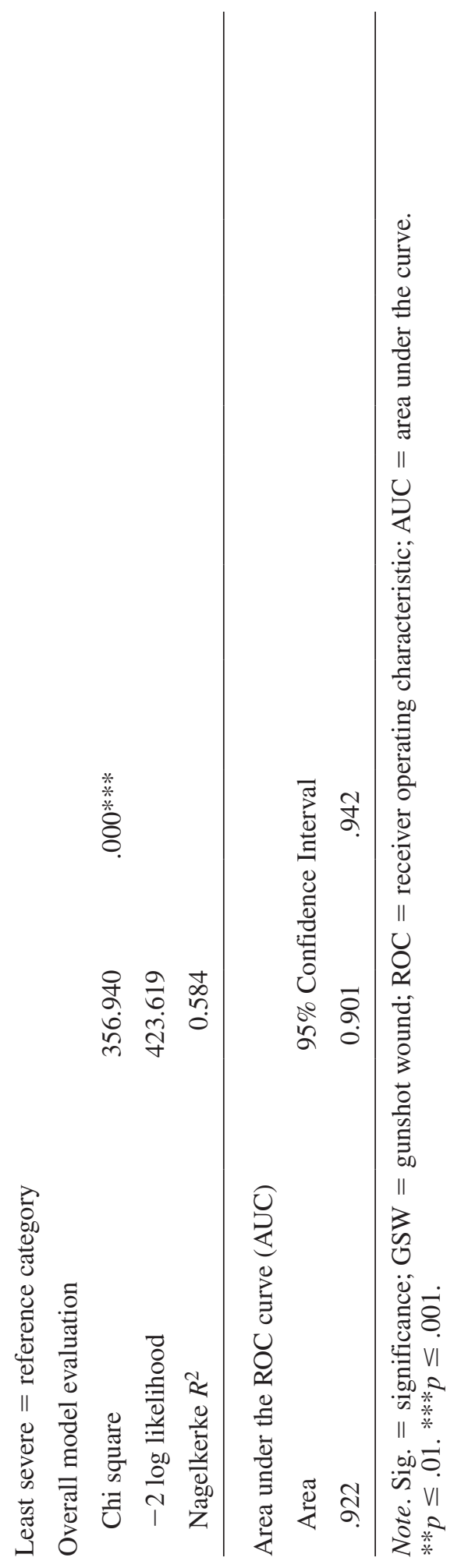




\section{Study Limitations}

The findings presented here should be interpreted with caution because there are several limitations to the study data. First, these data represent an 18-month period in one U.S. city and the data points come from law enforcement sources only. Historical data and detailed medical records on nonfatal shooting victims are not available for comparison or reliability checks. Detailed wound location data would have allowed for the use of the more detailed AIS and perhaps better modeling. Second, although not a significant covariate in any of the analyses, arrest record was limited to arrests that occurred in Marion County. As a binary variable, it captured prevalence, that is, whether or not the individual had been arrested or not, but not incidence or number of arrests for victims over time. Capturing arrest incidence, minimally in Marion County, but ideally more broadly, may create more variance and therefore more influence for the variable. In addition, almost one half of motives for the nonfatal shootings were unknown, whereas only $6 \%$ of homicide motives were unknown. As mentioned in the methods, the motive data source for nonfatal shooting serve as one-time, immediate case briefings and are not updated as case progresses. Similar to homicides, case details such as motive are not always available right away and may take time to cultivate. Any updating, for example, changing an unknown motive if it became known, would require the researchers to contact the case detective for follow-up. At this point in time, this is not logistically possible.

\section{DISCUSSION}

Initially, it seemed victims of nonfatal shootings were similar to gun homicide victims in Indianapolis during the study period. Both victim types tend to be young non-White males with a previous arrest record. Gunshot wound severity was most often "least severe," and the relationship of severe wounds to a homicide victim was expected. More times than not, gunshot victims, both fatal and nonfatal, were shot multiple times. Now, we return to the overarching RQ presented in this manuscript:

\section{RQ: Are nonfatal shooting victims different than gun homicide victims?}

The analysis presented here would support that nonfatal shooting victims are different than gun homicide victims especially as they relate to victim age, gunshot wound severity, and shooting motive. Somewhat surprising, although both victim arrest record and enduring multiple gunshot wounds were significant in the bivariate analyses indicating a relationship between each variable and victim type, neither were significant predictors of fatality. This, however, is most likely due to the lack of variability in the two covariates.

These analyses highlight the need for better gun violence data collection beyond what currently exists. Law enforcement, oftentime using federal funds, continues to spend time and resources to combat gun violence but is doing so without a complete picture of what is occurring. Relying on homicide data alone omits a considerable amount of information given the volume of gun violence that is not fatal. This research identifies a victim characteristic difference, specifically age —nonfatal shooting victims are on average 4.5 years younger than gun homicide victims. Although the data presented here cannot explain this difference, one could first speculate that the difference is a mere artifact of age itself. Simply, younger people tend to be stronger and healthier and perhaps, in this case, better 
able to recover from serious and/or multiple gunshot wounds. Or, this difference could be a result of unknown suspect (i.e., shooter) characteristics. Is the use of nonfatal gun violence more specific to the culture of younger actors? Perhaps it contributes to reputation or legitimacy within peer groups. Unfortunately, information on the suspects for nonfatal shooting incidents is difficult to capture. For cases that were part of this study, police identified a named suspect only $26 \%$ of the time. Similarly, research by Nance, Templeton, and O'Neill (1994) on pediatric gunshot cases revealed known suspects in only $23 \%$ of cases (excludes self-inflicted). Subsequently, there are most likely other important but not yet captured covariates that differ between nonfatal shooting and gun homicide victims.

Lack of data on nonfatal shootings is the status quo across the United States because cities still rely on UCR reporting as their principal data source and are slow to transition to NIBRS. ${ }^{7}$ Culling data on nonfatal shootings from current law enforcement records management systems has proven possible but can be challenging, resource intensive, and time-consuming (Hipple et al., 2016). Differing records management systems and internal operating procedures will make any nationwide uniform data collection system on gun violence all the more difficult. But, the need is clear. Minimally, police departments should attempt to routinely examine shooting trends-both fatal and nonfatal. And, although shooting injuries are captured by UCR within several crime categories (e.g., homicide, robbery, aggravated assault), perhaps it is time to consider a specific category or subcategory for gunshot wound victims, regardless of where the crime would fall according to the Hierarchy Rule.

The public health system strives to prevent harm to both individuals and the communities in which they live. Research in the public health field suggests that there is limited information about repeat victims presenting themselves at trauma centers. Referred to as the "revolving door" phenomenon (C. Cooper, Eslinger, Nash, Al Zawahri, \& Stolley, 2000, p. 837), this notion implies that victims of violence are admitted to emergency departments multiple times, and therefore, it is likely they live a high-risk lifestyle and are more apt to become a victim of a nonfatal shooting again. According to Howell et al. (2014), young, non-White males appear in hospital emergency departments at rates of 1.7-7.2 times higher than any other demographic of individuals. Although research shows individuals repeat as victims of nonfatal shootings, little is known how these experiences affects their lives and what violence means to them (Rich \& Grey, 2005). Gunshot wound injuries can cause prolonged physical and mental disabilities which can place a burden on society and the health care system (Howell et al., 2014; Rich \& Grey, 2005).

Gun violence prevention policy would be served well with more information about nonfatal shootings. It is hard to develop prevention programs without knowledge about motive. The motives behind why people are shooting each other and the factors that put individuals at risk for being shot and not killed are really not known. Missing motive data comprised almost $50 \%$ of nonfatal shooting cases in this study. However, drugs proved an important motive in this dataset, and therefore, a more holistic response to illicit drug trade contributors would make sense. That is, other responses in addition to those of traditional law enforcement might reduce gun violence fueled by the illicit drug trade.

One reason motive is hard to capture is nonfatal shooting victims do not always engage with law enforcement at the time of the incident. A fair amount of victims choose not to call 911 and transport themselves to emergency departments (Indianapolis Non-Fatal Shooting Review Board, 2014) and then refuse to or are physically unable to cooperate with the law enforcement investigation. Is this an issue of trust in the police or police 
legitimacy, or does the motive behind the shooting affect the decision to call for help? Or is there something else? Rich and Grey (2005) propose a hypothetical model of recurrent injury for young Black males who are victims of violence using Anderson's (1999) code of the street framework. The code of the street is a set of informal rules that govern behavior within the inner city and define how the role of respect is central to young Black males protecting themselves (Anderson, 1999). Rich and Grey suggest victims do not want to be viewed as the neighborhood "sucker," lack faith in the police, and suffer from traumatic stress and substance abuse.

The hospital emergency department can serve as an additional place for noninvestigatory and nonmedical data collection as well as response development. Violence prevention and intervention initiatives are not new to emergency departments or public health. C. Cooper et al. (2000) found that most of the risk factors for repeat victimization are specific behaviors (i.e., carrying a gun, drug dealing) and speak to an individual's lifestyle choices. Such findings are promising because it is conceivable a victim can change his or her behavior and lifestyle if provided with opportunity via a timely and effective intervention. Since law enforcement can only serve as one part of the response, research suggests that hospital emergency departments may be the most adequate environment to provide treatment and services, including violence prevention services. Victims may be more receptive to such services immediately following a traumatic gunshot wound. Services and treatment could help victims address drug addition, mental illness, and other behavioral changes (i.e., employment opportunities and education) that improve their current lifestyle choices (C. Cooper et al., 2000; Rich \& Grey, 2005).

The call to decrease gun violence is not new. However, the extant literature lacks research specific to nonfatal shootings to better inform policy and practice as it relates to gun violence reduction. Future research should build on these findings in several ways. Capturing more incident level detail about nonfatal shootings may help inform why some victims with very serious gunshot wounds survive and conversely some victims with less serious wounds do not survive. Relatedly, researchers need to understand "changeable" covariates because they relate to gun violence such as lifestyle, trust in law enforcement, incident location, transport time to hospitals, and so forth.

Research by Braga, Papachristos, and Hureau (2010) looked at both homicides and nonfatal shooting 8 incidents in Boston over a 29 -year period. Their work revealed that gun assaults followed the same patterns as homicides across micro-places. Likewise, data such as these presented here suggest that homicides and nonfatal shootings are closely related beyond just geography and may be differentiated by bullet wound location, motive, or covariates that have yet to be discovered. Sooner rather than later, gun violence research must include data on nonfatal shootings as well as gun homicides such as those presented here in an effort to establish improved data on all gun violence to better inform police and practice. This study strengthens the current research on both nonfatal and fatal gunshot wound victims by examining wound location and motive which can be used to better inform police and practice.

\section{NOTES}

1. NEDS data include injury identification as well as mechanism, intent, and severity of injury (https://www.hcup-us.ahrq.gov/nedsoverview.jsp).

2. http://www.cpsc.gov/en/Research—Statistics/NEISS-Injury-Data/ 
3. All but nine states have laws mandating physicians or health care facilities report gunshot wound injuries (i.e., injuries from a weapon) to local law enforcement (Gupta, 2007). Six of those nine states also do not mandate the reporting of injuries resulting from a crime.

4. All data sources were criminal justice data sources; that is, wound location information (considered medical data) did not come from hospital data sources because of Health Insurance Portability and Accountability Act regulations.

5. Figures generated January 25, 2016; nonfatal shooting and homicide data are subject to change.

6. The Quest number had to be related to a criminal arrest, not a family matter.

7. NIBRS was created to address some of the incident-based problems with UCR and allows for multiple crime types per incident as well as the isolation of incidents involving guns. However, adaptation of NIBRS by law enforcement agencies has been slow as only about one third of law enforcement agencies that participated in UCR reported via NIBRS in 2013 (FBI, 2015).

8. Assault and battery by means of a deadly weapon-firearm.

\section{REFERENCES}

Allison, P. D. (2002). Missing data (Vol. 136). Thousand Oaks, CA: Sage.

Anderson, E. (1999). Code of the street: Decency, violence, and the moral life of the inner city. New York, NY: Norton.

Annest, J. L., \& Mercy, J. A. (1998). Use of national data systems for firearm-related injury surveillance. American Journal of Preventive Medicine, 15(3 Suppl. 1), 17-30. http://dx.doi .org/10.1016/S0749-3797(98)00057-9

Azrael, D., Braga, A. A., \& O’Brien, M. E. (2013). Developing the capacity to understand and prevent homicide: An evaluation of the Milwaukee Homicide Review Commission. Boston, MA: Harvard School of Public Health.

Baker, S. P., \& O'Neill, B. (1976). The injury severity score: An update. The Journal of Trauma and Acute Care Surgery, 16(11), 882-885.

Baker, S. P., O’Neill, B., Haddon W., Jr., \& Long, W. B. (1974). The injury severity score: A method for describing patients with multiple injuries and evaluating emergency care. The Journal of Trauma and Acute Care Surgery, 14(3), 187-196.

Beaman, V., Annest, J. L., Mercy, J. A., Kresnow, M. J., \& Pollock, D. A. (2000). Lethality of firearmrelated injuries in the United States population. Annals of Emergency Medicine, 35(3), 258-266.

Black, D. J. (1970). Production of crime rates. American Sociological Review, 35(4), 733-748.

Black, D. J. (1980). Production of crime rates. In D. J. Black (Ed.), The manners and customs of the police (pp. 65-84). New York, NY: Academic Press.

Block, R. (1976). Homicide in Chicago: A nine-year study (1965-1973). Journal of Criminal Law and Criminology, 66(4), 496-510.

Block, R. (1977). Violent crime: Environment, interaction, and death. Lexington, MA: Lexington Books.

Blumstein, A. (1995). Youth violence, guns, and the illicit-drug industry. Journal of Criminal Law and Criminology, 86(1), 10-36.

Braga, A. A., Papachristos, A. V., \& Hureau, D. M. (2010). The concentration and stability of gun violence at micro places in Boston, 1980-2008. Journal of Quantitative Criminology, 26(1), 33-53. http://dx.doi.org/10.1007/s10940-009-9082-x

Cohn, D. V., Taylor, P., Lopez, M. H., Gallagher, C. A., Parker, K., \& Maass, K. T. (2013). Gun homicide rate down 49\% since 1993 peak; Public unaware. Retrieved from http://www .pewsocialtrends.org/2013/05/07/gun-homicide-rate-down-49-since-1993-peak-public-unaware/

Cook, P. J., \& Laub, J. H. (1998). The unprecedented epidemic in youth violence. In M. Tonry \& M. H. Moore (Eds.), Youth violence (Vol. 24, pp. 27-64). Chicago, IL: University of Chicago Press.

Cook, P. J., \& Laub, J. H. (2002). After the epidemic: Recent trends in youth violence in the United States. Crime and Justice, 29, 1-37. 
Cook, P. J., Lawrence, B. A., Ludwig, J., \& Miller, T. R. (1999). The medical costs of gunshot injuries in the United States. JAMA, 282(5), 447-454. http://dx.doi.org/10.1001/jama.282.5.447

Cooper, A., \& Smith, E. L. (2011). Homicide trends in the United States, 1980-2008: Annual rates for 2009 and 2010 (NCJ 236018). Washington, DC: U.S. Department of Justice. Retrieved from http://bjs.gov/content/pub/pdf/htus8008.pdf

Cooper, C., Eslinger, D. M., Nash, D., Al Zawahri, J., \& Stolley, P. D. (2000). Repeat victims of violence: Report of a large concurrent case-control study. Archives of Surgery, 135(7), 837-843. http://dx.doi.org/10.1001/archsurg.135.7.837

Decker, S. H. (1993). Exploring victim-offender relationships in homicide: The role of individual and event characteristics. Justice Quarterly, 10(4), 585-612.

DeMaris, A. (2004). Regression with social data: Modeling continuous and limited response variables (Vol. 417). Hoboken, NJ: Wiley.

Dobrin, A. (2001). The risk of offending on homicide victimization: A case control study. Journal of Research in Crime and Delinquency, 38(2), 154-173. http://dx.doi .org/10.1177/0022427801038002003

Federal Bureau of Investigation. (2004). Uniform crime reporting handbook. Retrieved from https:// www2.fbi.gov/ucr/handbook/ucrhandbook04.pdf

Federal Bureau of Investigation. (2013). Crime in the United States, 2012: Aggravated assault. Retrieved from https://www.fbi.gov/about-us/cjis/ucr/crime-in-the-u.s/2012/crime-in-theu.s.-2012/violent-crime/aggravated-assault

Federal Bureau of Investigation. (2015). Crime in the United States, 2014. Retrieved from https:// ucr.fbi.gov/crime-in-the-u.s/2014/crime-in-the-u.s.-2014/offenses-known-to-law-enforcement/ aggravated-assault

Felson, R. B., \& Steadman, H. J. (1983). Situational factors in disputes leading to criminal violence. Criminology, 21(1), 59-74. http://dx.doi.org/10.1111/j.1745-9125.1983.tb00251.x

Firearm \& Injury Center at Penn. (2011). Firearm injury in the United States. Philadelphia, PA: University of Pennsylvania.

Gove, W. R., Hughes, M., \& Geerken, M. (1985). Are uniform crime reports a valid indicator of the index crimes? An affirmative answer with minor qualifications. Criminology, 23(3), 451-502. http://dx.doi.org/10.1111/j.1745-9125.1985.tb00350.x

Grommon, E., \& Rydberg, J. (2014). Elaborating the correlates of firearm injury severity: Combining criminological and public health concerns. Victims \& Offenders, 1-23. http://dx.doi.org/10.10 $80 / 15564886.2014 .952472$

Gupta, M. (2007). Mandatory reporting laws and the emergency physician. Annals of Emergency Medicine, 49(3), 369-376. http://dx.doi.org/10.1016/j.annemergmed.2006.05.017

Hipple, N. K., McGarrell, E. F., O’Brien, M., \& Huebner, B. M. (2016). Gun crime incident reviews as a strategy for enhancing problem solving and information sharing. Journal of Crime and Justice, 1-18. http://dx.doi.org/10.1080/0735648X.2016.1155303

Howell, E. M., \& Abraham, P. (2013). The hospital costs of firearm assaults. Washington, DC: Urban Institute.

Howell, E. M., Bieler, S., \& Anderson, N. (2014). State variation in hospital use and cost of firearm assault injury, 2010. Washington, DC: Urban Institute.

Indianapolis Non-Fatal Shooting Review Board. (2014). Indianapolis Non-Fatal Shooting Review Board report. Indianapolis, IN: Author.

Jackson, P. G. (1990). Sources of data. In K. Kempf (Ed.), Measurement issues in criminology (pp. 21-50). New York, NY: Springer Publishing.

Linn, S. (1995). The injury severity score-importance and uses. Annals of Epidemiology, 5(6), 440-446. http://dx.doi.org/10.1016/1047-2797(95)00059-3

Long, J. S. (1997). Regression models for categorical and limited dependent variables. Thousand Oaks, CA: Sage.

Luckenbill, D. F. (1977). Criminal homicide as a situated transaction. Social Problems, 25(2), 176-186. http://dx.doi.org/10.2307/800293 
Maxfield, M. G. (1987). Lifestyle and routine activity theories of crime: Empirical studies of victimization, delinquency, and offender decision-making. Journal of Quantitative Criminology, 3(4), 275-282. http://dx.doi.org/10.1007/BF01066831

Miethe, T. D., \& Drass, K. A. (1999). Exploring the social context of instrumental and expressive homicides: An application of qualitative comparative analysis. Journal of Quantitative Criminology, 15(1), 1-21.

Mustaine, E. E. (2010). Lifestyle theory. In B. Fischer \& S. P. Lab (Eds.), Encyclopedia of victimology and crime prevention (pp. 1-10). Thousand Oaks, CA: Sage.

Nance, M. L., Templeton, J. M., Jr., \& O'Neill, J. A., Jr. (1994). Socioeconomic impact of gunshot wounds in an urban pediatric population. Journal of Pediatric Surgery, 29(1), 39-43. http:// dx.doi.org/10.1016/0022-3468(94)90519-3

Nocera, J. (2013, October 15). The gun report: October 15, 2013. The New York Times. Retrieved from https://nocera.blogs.nytimes.com/2013/10/15/the-gun-report-october-15-2013/

O'Brien, M., Woods, L., \& Cisler, R. A. (2007). The Milwaukee Homicide Review Commission: An interagency collaborative process to reduce homicide. Wisconsin Medical Journal, 106(7), 385-388.

Papachristos, A. V., Wildeman, C., \& Roberto, E. (2015). Tragic, but not random: The social contagion of nonfatal gunshot injuries. Social Science \& Medicine, 125(1), 139-150. http://dx.doi .org/10.1016/j.socscimed.2014.01.056

Piquero, A. R., MacDonald, J., Dobrin, A., Daigle, L. E., \& Cullen, F. T. (2005). Self-control, violent offending, and homicide victimization: Assessing the general theory of crime. Journal of Quantitative Criminology, 21(1), 55-71. http://dx.doi.org/10.1007/s10940-004-1787-2

Pizarro, J. M. (2008). Reassessing the situational covariates of homicides: Is there a need to disaggregate? Homicide Studies, 12(4), 323-349. http://dx.doi.org/10.1177/1088767908323741

Planty, M. G., \& Truman, J. (2013). Firearm Violence, 1993-2011 (NCJ 241730). Retrieved from https://www.bjs.gov/content/pub/pdf/fv9311.pdf

Pridemore, W. A. (2005). A cautionary note on using county-level crime and homicide data. Homicide Studies, 9(3), 256-268. http://dx.doi.org/10.1177/1088767905277202

Reiss, A. J., Jr., \& Roth, J. A. (1993). Understanding and preventing violence (Vol. 1). Washington, DC: National Academies Press.

Rich, J. A., \& Grey, C. M. (2005). Pathways to recurrent trauma among young black men: Traumatic stress, substance use, and the "code of the street." American Journal of Public Health, 95(5), 816-824. http://dx.doi.org/10.2105/AJPH.2004.044560

United States Census Bureau. (2015). QuickFacts beta. Retrieved from http://www.census.gov/ quickfacts/table/PST045214/1836003,00

United States Consumer Product Safety Commission. (n.d.). National Electronic Injury Surveillance System (NEISS). Retrieved from http://www.cpsc.gov/en/Research-Statistics/NEISS-InjuryData/

Wellford, C. F., Pepper, J. V., \& Petrie, C. V. (2005). Firearms and violence: A critical review. Washington, DC: National Academies Press.

Wolfgang, M. E. (1958). Patterns in criminal homicide. Philadelphia, PA: University of Pennsylvania Press.

Zahn, M. A., \& McCall, P. L. (1999). Homicides in the 20th-century United States. In M. D. Smith \& M. A. Zahn (Eds.), Studying and preventing homicide (pp. 10-30). Thousand Oaks, CA: Sage.

Acknowledgments. This project was supported by Award No. 2013-R2-CX-0015, awarded by the National Institute of Justice, Office of Justice Programs, U.S. Department of Justice. The opinions, findings, and conclusions or recommendations expressed in this publication/program/exhibition are those of the author(s) and do not necessarily reflect those of the Department of Justice.

Correspondence regarding this article should be directed to Natalie Kroovand Hipple, PhD, Indiana University, Department of Criminal Justice, 1033 East Third Street, 309 Sycamore Hall, Bloomington, IN 47405. E-mail: nkroovan@indiana.edu 